\title{
Comment
}

\section{Science journalism and digital storytelling}

\author{
Nico Pitrelli
}

\begin{abstract}
Among the most interesting aspects of the changes in the media ecosystem a leading role is played by the impact of digital and networking technologies on the ways news reports are built. In this Jcom commentary, the issues of the relationship between digital storytelling and professional news production will focus on science journalism. The commentary will deal with theoretical reflections and practical examples of innovative experiences in which different narration methods were exploited for scientific information.
\end{abstract}

How will science be in twenty or thirty years? Nobody can predict the future, yet many analysts do agree on the fact that it will be very different from present-day science. The researchers' work will change as there will be an exponential growth in scientific publishing, data availability and scientific authorship. ${ }^{1}$ Many are convinced that the key words of the new era will be networked science. ${ }^{2}$ Obviously, these are trends deriving from the impact of the Internet and digital technologies. These changes are visible even today, but will grow further over the next few years, according to the experts of scientific knowledge production dynamics. We do not know whether this will be good or bad, but if this analysis is correct, then the exponential growth of contents, data and authors shall have to face two important limitations more than it does today. On the one hand, people's attention will become a scarcer and scarcer resource. On the other hand, there will be an increased difficulty in drawing relevant and reliable information from the background noise. Both issues directly involve those who deal with science journalism.

In this framework, a workshop entitled "Science Journalism and Digital Storytelling" took place at SISSA in Trieste on 23 November $2011 .^{3}$ It was organised in the perspective of those wondering about the future of this sector, considering the impact of digital instruments on the professional production of scientific news. This Jcom commentary reports a few contributions presented at the workshop, which was organised and implemented considering the assumption that scientific journalism is permeated by negative trends, but it also has great opportunities, which are new and different from the past. Undoubtedly, it is one of the specialisation fields most affected by the tsunami that has hit paper journalism. At the same time, like never before, this appears the most suitable time to reshape methods, ways and processes of this profession as the crisis may affect the traditional editorial figures, but not science communication itself.

Facing all of these types of pressure, we are wondering whether scientific journalism will still be able to effectively report on the world of research, which is facing such a deep change, and to re-establish itself in the new media ecosystem as the most significant method in the definition of the public dimension of science. We are also wondering how it should change in order to do it.

One of the greatest issues to tackle is the ability to build reliable filters and services, able to help "readers" give a meaning to the unprecedented growth in the information produced by scientists and passed on about science over the next few years. The meeting at SISSA was aimed at exploring what and how much digital narration methods - such as mashups, timelines, videos, graphic animations, newsgames, live coverage - can offer to that purpose.

Among the most interesting aspects of the changes in the media ecosystem a leading role is played by the impact of interactive and multimedia technologies on the ways news reports are built. The digital ecosystem raises many questions for media professionals. For examples: what participation level can or should be included in the narration experience? To what extent should you focus on the contents or on the ability to build relationships? Those issues have always existed but they have acquired absolute centrality and an unprecedented relevance thanks to the new production, distribution and communication methods that have gained ground especially on the web. 
At the workshop, these topics were focused on science journalism through the presentation of theoretical reflections and practical experiences among the most significant ones at European level These include the experience of the German weekly magazine Der Spiegel, at the forefront in the socalled fact checking, i.e. in the rigorous check of the news reported by the media. Der Spiegel has a factchecking department employing 70 people and fully exploits the opportunities offered by the digitalisation of the sources to make sure facts do not get distorted in the process of adaptation to media formats. In his contribution, Maximilian Schäfer describes how fact-checking is applied to science journalism at Der Spiegel editorial office. Nicola Bruno tells a few of the most innovative experiences in digital journalism around the world. His is a journey full of surprises into tomorrow's information through the stories of visionary - and somewhat heroic - people who would like to change the way we look at the world. Finally, Richard Holliman illustrates the way reports about science in a digital age are becoming more distributed and participatory.

Digital storytelling is only one of the directions in which scientific journalism can and should be reinvented. Hopefully this Jcom commentary will not only favour subsequent analyses and criticism to that purpose, but also stimulate many others and contribute to consolidate studies in one of the most crucial information areas within a knowledge-based society.

Translated by Massimo Caregnato

\section{Notes and references}

1 J.-C. Burgelman et al. (2010), Science 2.0 (change will happen...), First Monday, 15 (7), available at: http://firstmonday.org/htbin/cgiwrap/bin/ojs/index.php/fm/article/view/2961/2573

2 M. Nielsen (2011), Reinventing Discovery: The New Era of Networked Science, Princeton University Press.

$3 \mathrm{http}: / /$ www.mappetrieste.it/cms/workshop.

How TO CITE: N. Pitrelli, Science journalism and digital storytelling, Jcom 10(04) (2011) C01 